\title{
Neonatal heel prick screening TSH concentration in the Netherlands as indicator of iodine status
}

\author{
Janneke Verkaik-Kloosterman (B)
}

\begin{abstract}
Background: Neonatal Thyroid Stimulating Hormone (nTSH) is proposed as indicator of iodine deficiency in a population. Population's iodine sufficiency is indicated by a proportion of the newborns less than $3 \%$ having nTSH above $5 \mathrm{mIU} / \mathrm{L}$. The aim of this study was to explore the Dutch neonatal heel prick screening TSH data to assess iodine status in the Netherlands and identify determinants and potential confounders of this assessment.

Methods: All newborns born in the Netherlands between 2007 and 2015 with a heel prick collection at day 3-7 were included $(n=1,435,600)$, except preterm neonates and baby's with a low birth weight. Total T4 was measured for all children, nTSH was measured in the $\sim 20 \%$ children with lowest total T4.

Results: The proportion with nTSH > 5mIU/L fluctuated between 0.6-1.3\% in 2007-2015. nTSH was significantly associated with laboratory performing the nTSH assay and age of heel prick sampling. The overall increasing trend in proportion $\mathrm{nTSH}>1 \mathrm{mlU} / \mathrm{L}$ was confounded by the laboratories with different and changed assays.

Conclusions: The low proportion neonates with high nTSH suggests a sufficient iodine status in the Netherlands. Whether the increased proportion $\mathrm{nTSH}>1 \mathrm{mIU} / \mathrm{L}$ over the years is an early indicator of deterioration of the iodine status remains unclear, due to differences and changes in analytical assays. nTSH might be a valuable and inexpensive way to get crude insight in the (trend in) iodine status, but more research is needed on the validity and potential conditions.
\end{abstract}

Keywords: lodine status, New-born TSH, Heel prick screening

\section{Background}

Adequate iodine intake is required for the production of thyroid hormones. These hormones regulate metabolic processes and play a crucial role in early growth and development of many organs, especially the brain [1]. Most growth and development of human brain happens during fetal life until 2-3 years postnatal life. Severe iodine deficiency in this period of life will result in irreversible mental retardation, and is also associated with other adverse effects including goiter, hypothyroidism, growth

Correspondence: Janneke.Verkaik@RIVM.nl

National Institute for Public Health and the Environment (RIVM), PO box 1, 3720 Bilthoven, BA, The Netherlands retardation, and increased risk of pregnancy loss $[1,2]$. In addition, emerging evidence shows that also mild iodine deficiency in early life is associated with a (persistent) negative effect on the cognitive development of the child [1, 3-6].

In European countries, severe iodine deficiency is uncommon, but signs of mild-to-moderate iodine deficiency have been observed in several countries [7-11]. Although the iodine concentration in the soil is low in the Netherlands [12], in the 2007 the World Health Organization (WHO) global database on iodine deficiency, the Netherlands is one of the countries scored with an adequate iodine intake [13]. This is based on

(c) The Author(s). 2021 Open Access This article is licensed under a Creative Commons Attribution 4.0 International License, which permits use, sharing, adaptation, distribution and reproduction in any medium or format, as long as you give appropriate credit to the original author(s) and the source, provide a link to the Creative Commons licence, and indicate if changes were made. The images or other third party material in this article are included in the article's Creative Commons licence, unless indicated otherwise in a credit line to the material. If material is not included in the article's Creative Commons licence and your intended use is not permitted by statutory regulation or exceeds the permitted use, you will need to obtain permission directly from the copyright holder. To view a copy of this licence, visit http://creativecommons.org/licenses/by/4.0/ The Creative Commons Public Domain Dedication waiver (http://creativecommons.org/publicdomain/zero/1.0/) applies to the data made available in this article, unless otherwise stated in a credit line to the data. 
urinary iodine concentration of children (6-18 yrs.) measured sub-nationally in the Netherlands in 1995-1996 [14]. In the Netherlands there is no nation-wide monitoring program for iodine not for adults nor for children. A Dutch regional study showed that the urinary iodine excretion of adults decreased since 2008, however the iodine intake is still expected to be adequate $[15,16]$. No recent iodine status data are available for Dutch children.

The Netherlands has a long history of iodization of salt, with bread being an important iodine source in the Dutch diet due to the addition of iodized salt [15]. Although mandatory fortification is legally not feasible in the Netherlands due to a court decision, mostly all bread is produced with iodized bakery salt containing 50-65 mg iodine per $\mathrm{kg}$ salt. This is due to a covenant [17] between the Ministry of Health and the conventional bakeries (industrial and traditional). For bakery products as well as bread replacing foods, a maximum concentration of $65 \mathrm{mg}$ iodine per $\mathrm{kg}$ salt is allowed. Kitchen salt and foods other than bread may also voluntarily be produced with iodized salt, with a maximum concentration of $25 \mathrm{mg}$ iodine per $\mathrm{kg}$ salt. However, for foods other than bread, iodized salt is used on a small-scale [15]. The observed decrease in urinary iodine excretion in Dutch adults in 2008, may be related to the effort to decrease the population's salt intake. To reduce the population's salt intake, the legal maximum amount of salt in bread was gradually reduced in the Netherlands, from $2.5 \%$ dry matter to $2.1 \%$ dry matter in July 2009 to $1.8 \%$ dry matter in January 2013. As a consequence, the iodine content of bread is decreased. However, no reduction in salt intake was observed in this period $[16,18]$. In addition, an important factor is changes in the Dutch iodine policy to meet the European regulation on mutual recognition. The last revision of the Dutch iodine policy was in 2008 [19], resulting in an expansion of the foods allowed to contain iodized salt. Instead of a few food groups allowed to contain iodized salt (e.g. bread, processed meat products, kitchen salt), iodized salt may be added to all food groups, except unprocessed foods and drinks with $>1.2 \mathrm{vol} \%$ alcohol. The iodine levels in the specific food groups allowed to contain iodized salt prior to 2008 , were set taking into account the iodine intake and consumption from these food groups. With the expansion of the foods that may contain iodized salt since 2008, the allowed maximum iodine content in salt was reduced with $7-38 \%$ compared to the situation prior to 2008. This was done to prevent too high iodine intakes if more foods potentially containing iodized salt would be consumed.

Measuring the urine iodine concentration is thought to assess the population's iodine status adequately [20]. In addition, thyroid volume, serum thyroglobulin concentration and neonatal thyroid-stimulating hormone (nTSH) are proposed to assess a population's iodine status $[12,21]$. TSH seems only a sensitive indicator of iodine status in newborns. The thyroid of neonates has, in comparison with adults, a small iodine storage and a high iodine turnover rate. With a low iodine supply, increased TSH will maintain the high iodine turnover [22]. Sufficient iodine intake at the population level is indicated by less than $3 \%$ with a nTSH concentration exceeding $5 \mathrm{mIU} / \mathrm{L}$. Higher proportions of $3-19.9 \%$ indicate mild iodine deficiency, of $20-39.9 \%$ indicate moderate deficiency, and above $39.9 \%$ indicate severe iodine deficiency [23]. The WHO proposed that existing newborn blood screenings programs can be used to assess iodine status in a population [1]. In addition, it can be used to study the effect of (changes in) iodination programs on the population's iodine status.

The aim of this study was to examine the Dutch neonatal heel prick screening TSH data of 2007-2015 A) to estimate the percentage of blood spot TSH $>5 \mathrm{mIU} / \mathrm{L}$ to assess iodine sufficiency in the Netherlands in the years 2007 to 2015, and B) to pick-up a potential increase in $\mathrm{nTSH}$ values due to the known decrease in iodine intake in the Dutch adult population.

\section{Methods \\ Data collection Dutch neonatal heel prick screening program}

This study is a secondary data analyses of extant data. For this study we statistically re-analysed TSH and $\mathrm{T}_{4}$ data already collected and chemically analysed for the Dutch neonatal heel prick screening program for congenital hypothyroidism; no additional data was collected nor chemically analyses. A more detailed description of this screening program is provided by Verkerk et al. [24]. In brief, the Dutch nationwide neonatal screening program for congenital hypothyroidism $(\mathrm{CH})$ was initiated in 1981. Neonatal heel prick blood was collected between $72 \mathrm{~h}$ to $168 \mathrm{~h}$ after the delivery. Blood samples were dried and analysed within 7 days at one of the five regional laboratories (i.e. Academic Medical Center, Amsterdam; National Institute for Public Health and the Environment, Bilthoven; IJsselland Hospital, Capelle a/d IJssel; St. Elisabeth Hospital, Tilburg; Isala Clinics, Zwolle).

The Dutch neonatal heel prick (blot spot) screening program is part of the National Population Screening Programme in the Netherlands funded by the State and falls under the Dutch Population Screening Act. For our study no additional ethical approval was necessary, because neither extra specimens nor additional chemical analyses were required, in addition the provided dataset was anonymised, and consent for additional scientific research was provided. The data was provided by the 
working group management information of Praeventis. Praeventis is the registration system of the Dutch national vaccine provision and prevention program, which includes the neonatal screening [25].

\section{Study population}

Heel-prick samples of children born between January 1, 2007 and December 31, 2015 were included in the present study. This resulted in a total sample of 1,611, 391 children, which varied between 171,138 children in 2015 to 185,271 children in 2009. Participation rate was high; > 99\% [26, 27].

Children with missing data for $\mathrm{T}_{4}$ or nTSH concentration, age at heel prick sampling, pregnancy duration, birth weight or laboratory were excluded $(n=47,380$; $2.9 \%)$. In addition, children with a heel prick at $<3$ days or $>7$ days of age were excluded $(n=17,618 ; 1.1 \%)$, as well as children with a low birthweight $(\leq 2500 \mathrm{~g}, n=50$, $165 ; 3.1 \%$ ) and children born preterm (gestational age $\leq$ 36 weeks, $n=59,679 ; 3.7 \%)$, since these factors may influence nTSH concentration [28]. Children with a coded birth weight $(7.77 \mathrm{~kg}$ or more) and pregnancy duration ( $>45$ weeks) were excluded, as these numbers are not reflecting actual birth weight and pregnancy duration $(n=60,628 ; 3.8 \%)$. The final study sample after exclusions consisted of $1,435,600$ children (i.e. $89 \%$ of the total sample).

\section{Analysis of dried blood samples}

In the Netherlands, the screening for $\mathrm{CH}$ is different compared to many other countries [29]. In most countries newborns are screened for primary $\mathrm{CH}$ (defect in thyroid) only. In these countries, nTSH is measured first, subsequently total $\mathrm{T}_{4}$ or $\mathrm{T}_{4}$ is measured only in infants with raised nTSH. In the Netherlands, besides primary $\mathrm{CH}$ newborns are also screened for central $\mathrm{CH}$ (defect in hypophysis or hypothalamus) and therefore, total $\mathrm{T}_{4}$ is measured first, followed by $\mathrm{nTSH}$ in the infants with lowest total $\mathrm{T}_{4}$ [24]. In the screening for $\mathrm{CH}$, total $\mathrm{T}_{4}$. (thyroxin) concentration, expressed as the number of standard deviations (SD) from the daily average, was determined for all infants (further referred to as 'total population'). For samples with a total $\mathrm{T}_{4}$ concentration $\leq$ - 0.8 SD, i.e. circa $20 \%$ of all newborns, nTSH concentration (mIU/l whole blood) was also determined from the same filter paper cards with dried blood spots (further referred to as 'TSH-subpopulation') [24]. In addition, for newborns with a total $\mathrm{T}_{4}$ concentration $\leq-$ 1.6 SD (about 5\% of all infants) also thyroid-binding globulin (TBG) was determined. According to the screening procedures, TSH estimates were available as integers. Children with very low $\mathrm{T}_{4}$ concentration or very high nTSH concentration were referred to a paediatrician. A second heel prick was performed if there were slight deviating T4:TBG ratio or nTSH concentrations [24].

Total $\mathrm{T}_{4}$ and $\mathrm{nTSH}$ concentrations were analysed in $3.2 \mathrm{~mm}$ punches of blood spots on newborn screening filter paper cards. As of January 1, 2007, concentrations of $\mathrm{T}_{4}$ were determined with an automated assay using the AutoDelfia or GSP platform (PerkinElmer, Turku, Finland), and concentrations of nTSH with these same platforms (laboratory Zwolle: AutoDelfia; laboaratories Bilthoven, Capelle a/d IJssel, Tilburg AutoDelfia later GSP platform) or a commercial manual ELISA (laboratory Amsterdam; Thermofisher Scientific, Waltham, MA). The analytical methods used in the screening program have gradually been replaced as they became obsolete and cut-off values have been updated. Since 2010 for $\mathrm{T}_{4}$ the $\mathrm{SD}$ is not calculated based on the daily average, but is based on a standard value for the variation coefficient in the population of 22\%. In February 2012 the Bilthoven laboratory, and in April 2013 the laboratories in Capelle a/d IJssel and Tilburg exchanged the AutoDelfia for the GSP platform. As results from the GSP platform were lower than those measured with the AutoDelfia, for harmonisation of the results TSH concentrations were multiplied with a factor of 1.25. After re-evaluation the use of the nTSH factor lapsed since May 2016. Therefore, in our study we used the uncorrected $\mathrm{nTSH}$-values.

If the $\mathrm{T}_{4}$ or nTSH measurement was not reliable, for example due to insufficient filling of the array, a second measurement was collected. Since the second measurement was considered more accurate, this estimate was included in our analyses.

\section{Statistical analyses}

Blood spot total $\mathrm{T}_{4}$ and $\mathrm{nTSH}$ were tabulated by year of birth, gender, age at heel prick sampling, birth weight, pregnancy duration, season at heel prick sampling, and laboratory. For $\mathrm{T}_{4}$ this was done separately for the total population and the nTSH-subpopulation.

Analyses involving group comparison were performed using Kruskall-Wallis $\mathrm{H}$ test, those involving two continuous variables were performed using Spearman correlation. Associations were illustrated using histograms. Statistical analyses for which the magnitude of the differences was small (Kruskal-Wallis $H$ test: $\chi^{2}<150$ or Spearman correlations: rho $<0.05)$ were considered not relevant, even though these might be statistically significant based on the $p$-value. Cochrane Mantel-Haenzel test was performed to study if there was a trend over the calendar years between a category of TSH and each category of the characteristics found to be statistically significant in the previous described analyses. All statistical analyses were performed at a 5\% level of significance, which was Bonferonni-adjusted for multiple testing to 
$0.19 \%$ (i.e. 0.05 divided by 27 different analyses). All statistical analyses were performed with SAS software version 9.4 (SAS Institute Inc., Cary, NC).

Univariate logistic regression was applied to estimate the effects of year of birth, gender, age at heel prick sampling, birth weight, pregnancy duration, season at heel prick sampling, laboratory on the change of TSH exceeding a pre-specified cutoff point. Results were only presented for the characteristics considered relevant (see above). A cutoff of $5 \mathrm{mIU} / \mathrm{L}$ was chosen, as this is the cut point provided by WHO to assess iodine status using nTSH. In addition, a cutoff of $1 \mathrm{mIU} / \mathrm{L}$ was selected, as the raw data indicated a potential change over the years in the categories with 1 and $2 \mathrm{mIU} / \mathrm{L}$. To correct for potential confounders, also multivariate logistic regression was applied, taking all earlier studied characteristics into account, as well as relevant interaction terms.

\section{Results}

\section{General characteristics of the population}

Of the children included in this study, $51 \%$ were male, almost $90 \%$ of heel prick blood was sampled at the age of 46 days, median birth weight was $3.5 \mathrm{~kg}$, and median gestational age was 280 days (i.e. 40 weeks; Table 1). Overall most births were in autumn and there was some fluctuation over the years (Table 1 and Online Supplemental Material Table 1). For birth season, age heel prick, and laboratory there was a statistically significant fluctuation over the years (Online Supplemental Material Table 1).
However the differences over the years were small with an exception of year 2010 in which there were more children born in winter and less in summer compared to the other years. Over the years, the proportion of heel prick sample collected on day 3 increased from 4 to 10\%. This increase of almost $55 \%$ was accompanied by a decrease of $4 \%$ in the proportion of heel prick sample collection on day 4, 5, and 6 and a decrease of $60 \%$ on day 7 (Online Supplemental Material Table 1). Overall the laboratories of Tilburg and Zwolle analysed the lowest proportion of measurements (Table 1). These proportions were similar for most years, with the exception of 2009 and 2010 with fewer samples being analysed in the laboratory of Tilburg. (Online Supplemental Material Table 1).

The nTSH-subpopulation was about $20 \%$ of the total study population, as expected. In the nTSHsubpopulation, the proportion male was higher (59\%), as well as the proportion with collection of heel prick sample on day 6 and 7 (Table 1) in comparison with the total population. In addition, the pregnancy duration was shorter (median 277 days) compared to the total population. The fluctuations over the years for the studied characteristics in the nTSH-subpopulations were similar to the fluctuations over the years for total population (Online Supplemental Material Table 1).

\section{Neonatal $\mathrm{T}_{4}$ levels}

The median (P5-P95) total $\mathrm{T}_{4}$ showed some variation over the calendar years and varied from 83 (57-118)

Table 1 Characteristics of the study population presented as count (sample size), median (5th-95th percentile: pregnancy duration, birth weight), or percentage (gender, season at birth, age at heel prick, laboratory)

\begin{tabular}{|c|c|c|c|c|c|}
\hline \multirow[t]{2}{*}{$\mathrm{N}$} & \multirow[b]{3}{*}{ male } & \multicolumn{2}{|c|}{ total population } & \multicolumn{2}{|c|}{ nTSH subpopulation } \\
\hline & & $1,435,600$ & & 264,407 & \\
\hline Gender (\%) & & 51 & $x^{2}=1017,1$ d.f., $p<0.0001$ & 59 & $x^{2}=9074,1$ d.f., $p<0.0001$ \\
\hline \multirow[t]{4}{*}{ Season at birth (\%) } & spring & 24 & $x^{2}=2850,3$ d.f., $p<0.0001$ & 24 & $x^{2}=826,3$ d.f., $p<0.0001$ \\
\hline & summer & 24 & & 24 & \\
\hline & autumn & 27 & & 27 & \\
\hline & winter & 25 & & 25 & \\
\hline \multirow[t]{5}{*}{ Age at heel prick (\%) } & day 3 & 8 & $x^{2}=1,007,684,4$ d.f., $p<0.0001$ & 7 & $x^{2}=148,329,4$ d.f., $p<0.0001$ \\
\hline & day 4 & 50 & & 46 & \\
\hline & day 5 & 24 & & 24 & \\
\hline & day 6 & 15 & & 19 & \\
\hline & day 7 & 3 & & 4 & \\
\hline \multirow[t]{5}{*}{ Laboratory (\%) } & Amsterdam & 20 & $x^{2}=34,673,4$ d.f., $p<0.0001$ & 20 & $x^{2}=6307,4$ d.f., $p<0.0001$ \\
\hline & Bilthoven & 21 & & 21 & \\
\hline & Capelle & 25 & & 25 & \\
\hline & Tilburg & 17 & & 17 & \\
\hline & Zwolle & 17 & & 17 & \\
\hline Pregnancy duration (days) & & $280(262-292)$ & & $277(260-291)$ & \\
\hline Birth weight (kg) & & $3.5(2.8-4.3)$ & & $3.4(2.7-4.2)$ & \\
\hline
\end{tabular}


$\mathrm{nmol} / \mathrm{l}$ in 2008 to $91(62-128) \mathrm{nmol} / \mathrm{l}$ in 2015 (Table 2). This value was lower for male than female $(p<0.0001$ each year, Online Supplemental Material Table 2). In addition, the median total $\mathrm{T}_{4}$ level increased with birth weight ( $p<0.0001$ each year) and pregnancy duration $(p<0.0001$ each year) and was lower for data collected on day 6 or 7 compared to days 3-5 $(p<0.0001$ each year). There was no relevant variation over the years for total T4 and each of the studied characteristics (Online Supplemental Material Table 2).

As expected, the median (P5-P95) total $\mathrm{T}_{4}$ was lower for the nTSH-subpopulation compared to the total population of new-borns, as they were selected based on lowest total $\mathrm{T}_{4}$. The median total $\mathrm{T}_{4}$ showed some variation over the calendar years ranging from 62 (46-74) $\mathrm{nmol} / \mathrm{l}$ in 2008 to $68(52-79) \mathrm{nmol} / \mathrm{l}$ in 2010 (Table 2), however based on the small $\chi^{2}$ this was not considered relevant. In this nTSH-subpopulation, the difference in total T4 was not as pronounced as in the total population for gender, birth weight, and pregnancy duration. (Online Supplemental Material Table 2). Similar to the total population, there was no relevant variation over the years for total T4 and each of the studied characteristics in the nTSH-subpopulation (Online Supplemental Material Table 2).

\section{Distribution of $n$ TSH-levels}

In each calendar year, about $90 \%$ of the nTSHsubpopulation had a rounded nTSH value of 1 or 2 mIU/L. The Kruskal-Wallis $\mathrm{H}$ test showed that there was a statistically significant difference in nTSH levels between the calendar years $\left(\chi^{2}=8149,8\right.$ d.f., $p<0.0001)$. Most children had a rounded nTSH value of $1 \mathrm{mIU} / \mathrm{l}$, however this percentage decreased from 69 to $74 \%$ in the calendar years $2007-2012$ to $50 \%$ in 2015 . With this decrease there was a joint increase in children with a rounded nTHS level of $2 \mathrm{mIU} / \mathrm{L} ; 17-21 \%$ in 2007 2012 to $39-42 \%$ in $2014-2015$. The percentage children in each of the higher nTSH categories $(3 \mathrm{mIU} / \mathrm{L}$ or higher) remained below 8\% (Fig. 1a \& Online Supplemental Material Table 3a). In addition there was a statistically significant difference in nTSH levels between the laboratories (Kruskal-Wallis $\mathrm{H}$ test: $\mathrm{X}^{2}=7195,4$ d.f., $p<0.0001)$. The nTSH distributions were similar for the laboratories in Bilthoven, Capelle and Tilburg, but the
nTSH values in Zwolle tended to be lower (especially in 2012-2015) and those in Amsterdam higher (Fig. 1b \& Online Supplemental Material Table 3b). The distribution of nTSH levels differed significantly across the ages at heel prick sampling (Fig. 1c \& Online Supplemental Material Table 3c; Kruskal-Wallis $H$ test: $\chi^{2}=482$, 4 d.f., $p<0.0001$ ), with the lowest nTSH values at day 5 . For the characteristics gender, pregnancy duration, birth weight, and season statistical significant differences $(P<0.0001)$ in $\mathrm{nTSH}$ values were observed, however the magnitude of the differences was small (Kruskal-Wallis $H$ test: $X^{2}<150$ or Spearman correlations: rho $<0.05$ ) and therefore considered not relevant. The proportion new-borns with nTSH value equal to $1 \mathrm{mIU} / \mathrm{L}$ over the calendar years varied statistically significantly across laboratories (Cochran Mantel-Haenzel test $\mathrm{X}^{2}=p<0.0001$ (Table 3). The laboratories Bilthoven, Capelle, and Tilburg showed a steep decrease in the proportion newborns with $\mathrm{nTSH}=1 \mathrm{mIU} / \mathrm{L}$, however in the laboratory of Zwolle there was a small decrease since 2010 which remained constant in later years. Over the years the proportion new-borns with $\mathrm{nTSH}=1 \mathrm{mIU} / \mathrm{L}$ measured in the laboratory of Amsterdam showed first an increase and in the last two years a decrease. The proportion new-borns with a nTSH value equal to $1 \mathrm{mIU} / \mathrm{L}$ over the calendar years varied statistically significantly across ages of heel prick sampling (Cochran Mantel-Haenzel test $\left.x^{2}=p<0.0001\right)$. A decrease in percentage of neonates with a nTSH value of $1 \mathrm{mIU} / \mathrm{L}$ was observed for day 3-6 (Table 3). For day 7, this percentage showed first an increase and then a decrease.

The observed changes in the distribution of proportions with a specific rounded nTSH value for the different categories of calendar year, laboratory, and age at heel prick sampling were quantified in univariate logistic regression models. As in the Figs. 1a-c the largest differences were observed for the category nTSH $1 \mathrm{mIU} / \mathrm{L}$, logistic regression was applied for $\mathrm{nTSH}>1 \mathrm{mIU} / \mathrm{l}$ versus $\mathrm{nTSH}=1 \mathrm{mIU} / \mathrm{L}$. Until 2012, there were relatively small differences in percentage with $\mathrm{nTSH}>1 \mathrm{mIU} / \mathrm{L}$ (odds ratio 0.9-1.2). Starting at 2013, there was an increase in percentage of children with $\mathrm{nTSH}>1 \mathrm{mIU} / \mathrm{L}$ (odds ratio 1.6-2.6), which seemed to stabilize in 2014-2015 (Fig. 2). The percentage $\mathrm{nTSH}>1 \mathrm{mIU} / \mathrm{L}$ was highest for Amsterdam (odds ratio 2.95 compared to Zwolle), also

Table 2 Dried blood spot total $\mathrm{T}_{4}$ concentration (nmol/L) per calendar year (median (P5-P95) for total neonatal population and TSH subpopulation (Kruskall-Wallis)

\begin{tabular}{|c|c|c|c|c|c|c|c|c|c|c|}
\hline & \multicolumn{9}{|c|}{ Total $\mathrm{T}_{4}(\mathrm{nmol} / \mathrm{L})$} & \multirow[t]{2}{*}{$p$-value } \\
\hline & 2007 & 2008 & 2009 & 2010 & 2011 & 2012 & 2013 & 2014 & 2015 & \\
\hline $\begin{array}{l}\text { Total } \\
\text { population }\end{array}$ & $87(58-126)$ & $\begin{array}{l}83(57- \\
118)\end{array}$ & $\begin{array}{l}85(58- \\
120)\end{array}$ & $\begin{array}{l}90(63- \\
127)\end{array}$ & $\begin{array}{l}88(61- \\
125)\end{array}$ & $\begin{array}{l}87(60- \\
123)\end{array}$ & $\begin{array}{l}86(60- \\
122)\end{array}$ & $\begin{array}{l}86(59- \\
122)\end{array}$ & $\begin{array}{l}91(62- \\
128)\end{array}$ & $\begin{array}{l}x^{2}=40,8 \text { d.f., } p< \\
0.0001\end{array}$ \\
\hline $\begin{array}{l}\text { TSH- } \\
\text { subpopulation }\end{array}$ & $64(48-77)$ & $62(46-74)$ & $64(47-77)$ & $68(52-79)$ & $66(50-78)$ & $65(49-77)$ & $65(49-77)$ & $65(48-76)$ & $68(51-80)$ & $\begin{array}{l}x^{2}=150,8 \text { d.f., } p< \\
0.0001\end{array}$ \\
\hline
\end{tabular}



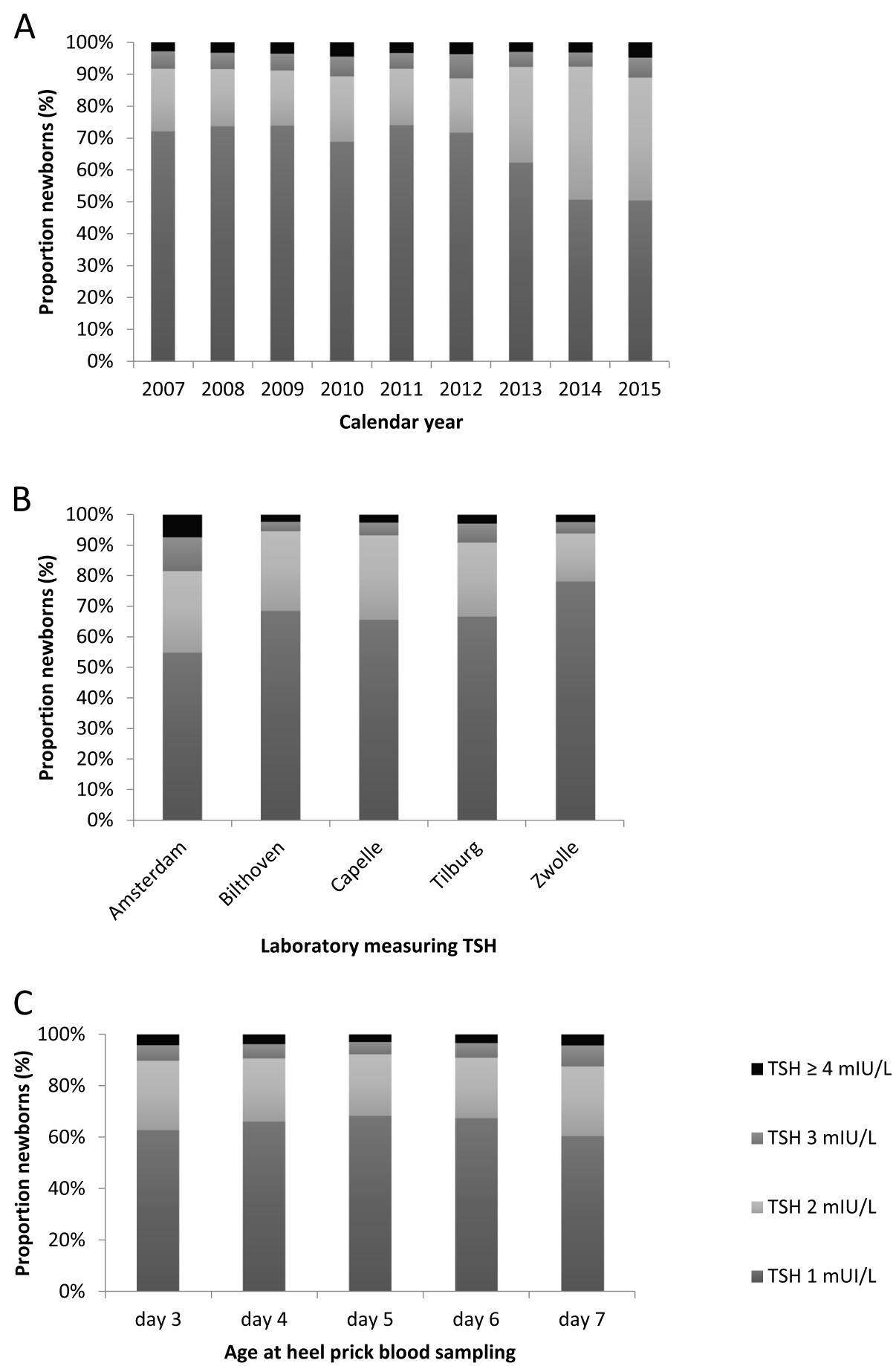

Fig. 1 Distribution of rounded nTSH values measured in heel prick blood of new-borns in the Netherlands, $\mathbf{A}$ in each calendar year - KruskalWallis H test $X^{2}=8149 P<0.0001$, B for each laboratory - Kruskal-Wallis $H$ test $X^{2}=7195 P<0.0001$, C across ages at heel prick sampling - KruskalWallis test $X^{2}=482 P<0.0001$

the laboratories Bilthoven, Capelle, and Tilburg had a higher percentage compared to Zwolle (odds ratio 1.651.87). The percentage children with $\mathrm{nTSH}>1 \mathrm{mIU} / \mathrm{L}$ was lowest for day 5 (odds ratio 0.78 compared to day 3), and highest for day 7 (odds ratio 1.1 compared to day
3) (Fig. 2a). Results from a multivariate logistic regression model showed that there was a statistically significant interaction between year and laboratory $(p<$ $0.0001)$, laboratory and age $(p<0.0001)$, and year and age $(p=0.0004)$. Figure $2 \mathrm{~b}$ shows the odds ratios for the 
Table 3 Proportion (\%) new-borns with TSH = $1 \mathrm{mlU} / \mathrm{L}$ in heel prick blood by laboratory and calendar year and by age at heel prick screening and calendar year (both Cochran-Mantel-Haenzel test)

\begin{tabular}{lllllllllll}
\hline & $\mathbf{2 0 0 7}$ & $\mathbf{2 0 0 8}$ & $\mathbf{2 0 0 9}$ & $\mathbf{2 0 1 0}$ & $\mathbf{2 0 1 1}$ & $\mathbf{2 0 1 2}$ & $\mathbf{2 0 1 3}$ & $\mathbf{2 0 1 4}$ & $\mathbf{2 0 1 5}$ & $\boldsymbol{p}$-value \\
\hline Laboratory & & & & & & & & & \\
Zwolle & 78.74 & 85.66 & 84.54 & 74.08 & 76.38 & 75.45 & 77.37 & 75.17 & 75.47 & $<\mathbf{0 . 0 0 0 1}$ \\
Tilburg & 83.84 & 81.77 & 74.96 & 78.16 & 78.52 & 69.46 & 55.27 & 39.9 & 44.21 & $<\mathbf{0 . 0 0 0 1}$ \\
Capelle & 76.16 & 78.85 & 77.18 & 73.29 & 72.56 & 69.99 & 57.71 & 40.6 & 48.98 & $<\mathbf{0 . 0 0 0 1}$ \\
Bilthoven & 80.02 & 84.64 & 80.02 & 73.87 & 78.36 & 69.11 & 52.84 & 43.25 & 50.72 & $<\mathbf{0 . 0 0 0 1}$ \\
Amsterdam & 43.2 & 39.04 & 55.11 & 48.78 & 65.2 & 75.85 & 72.76 & 62.55 & 36.25 & $<\mathbf{0 . 0 0 0 1}$ \\
Age & & & & & & & & & \\
day 3 & 71.27 & 74.62 & 74.77 & 66.58 & 69.64 & 67.69 & 59.02 & 47.00 & 49.81 & $<\mathbf{0 . 0 0 0 1}$ \\
day 4 & 72.71 & 75.73 & 74.76 & 69.55 & 73.08 & 69.79 & 60.21 & 48.97 & 50.30 & $<\mathbf{0 . 0 0 0 1}$ \\
day 5 & 74.19 & 76.27 & 76.37 & 71.59 & 76.04 & 73.57 & 64.05 & 51.89 & 51.92 & $<\mathbf{0 . 0 0 0 1}$ \\
day 6 & 72.08 & 72.00 & 70.72 & 66.78 & 75.46 & 75.66 & 67.33 & 55.27 & 50.41 & $<\mathbf{0 . 0 0 0 1}$ \\
day 7 & 61.44 & 52.78 & 65.08 & 59.22 & 79.39 & 73.92 & 65.44 & 51.93 & 44.94 & $\mathbf{0 . 0 0 0 4}$ \\
\hline
\end{tabular}

probability that $\mathrm{nTSH}>1 \mathrm{mIU} / \mathrm{L}$ of the calendar years per laboratory for age of heel prick sampling is 4 days. Although there were differences in odds ratio values for the trend over the years for each laboratory per age of heel prick blood sampling, the pattern over the years was similar for each age of heel prick blood sampling for a specific laboratory (data not shown). For the laboratories of Bilthoven, Tilburg, and Capelle the trend over the years was similar, with an increasing odds ratio starting at 2009-2010 (Fig. 2b). This means that from 2009 to 2010 the proportion children with $\mathrm{nTSH}>1 \mathrm{mIU} / \mathrm{L}$ increased compared to 2007. For the laboratory of Zwolle also an increase in the proportion children with nTSH > $1 \mathrm{mIU} / \mathrm{L}$ was observed starting at 2010, however it remained more or less stable in the period 2010-2015 (odds ratio range 1.03-1.22). In contrast, the laboratory of Amsterdam first showed a decrease in the proportion children with $\mathrm{nTSH}>1 \mathrm{mIU} / \mathrm{L}$ compared to 2007 , and starting round 2013 this proportion seemed to increase compared to the years before. In general the proportions with $\mathrm{nTSH}>1 \mathrm{mIU} / \mathrm{L}$ were higher for Amsterdam compared to the other laboratories (Table 3).

\section{Evaluation of the population's iodine status}

According to WHO, iodine intake at the population level is sufficient if the percentage of nTSH concentration exceeding $5 \mathrm{mIU} / \mathrm{L}$ is below 3\% [23]. The proportion with a nTSH value $>5 \mathrm{mIU} / \mathrm{L}$ almost doubled in our sample, from about $0.6 \%$ in 2007 to $1.1 \%$ in 2015 (Online Supplemental Material Table 3a). However, there is variation over the calendar years, with a marked high percentage of $1.3 \%$ in 2010 . In addition, for age at heel prick sampling and laboratory there were variations in the proportion with a TSH-value $>5 \mathrm{mIU} / \mathrm{L}$ (Online Supplemental Material Tables 3b-c). Over the calendar years there was a trend in increasing proportion of new-borns with
nTSH $>5 \mathrm{mIU} / \mathrm{L}$ in the laboratories of Tilburg (Cochran Mantal-Haenzel value 9.7894, $p=0.0018)$, Capelle (Cochran Mantal-Haenzel value 4.0181, $p=0.0450$ ), and Bilthoven (Cochran Mantal-Haenzel value 5.8333, $p=$ 0.0157) (Table 4). For the other laboratories, no such trend was observed. In each calendar year, the proportion with $\mathrm{nTSH}>5 \mathrm{mIU} / \mathrm{L}$ remained below $3 \%$. However, in the laboratory of Amsterdam this proportion was around $2.5 \%$ in 2010 and 2015, in the other calendar years it was between 0.96 and $1.59 \%$. There was no statistically significant trend over the calendar years between nTSH $>5 \mathrm{mIU} / \mathrm{L}$ and age at heel prick sampling (Table 4), except for day 7 (Cochran Mantal-Haenzel value $4.7671, p=0.0290$ ).

These changes in $\mathrm{nTSH}>5 \mathrm{mIU} / \mathrm{L}$ were also quantified with univariate logistic regression, showing a higher percentage with $\mathrm{nTSH}>5 \mathrm{mIU} / \mathrm{L}$ at day 3 and 4 (odds ratio 0.98-1.00) compared to days 5-7 (odds ratio 0.70-0.72; Fig. 3a). The percentage with $\mathrm{nTSH}>5 \mathrm{mIU} / \mathrm{L}$ was in the laboratory of Amsterdam higher compared to the other laboratories; odds ratio 2.57 compared to the laboratory in Zwolle (Fig. 3a). Results from a multivariate logistic regression model showed that there was a statistically significant interaction between year and laboratory $(p<0.0001)$. Figure 3b shows the odds ratios for the probability that $\mathrm{nTSH}>5 \mathrm{mIU} / \mathrm{L}$ for each of the calendar years per laboratory for age of heel prick sampling is 4 days. Although there were differences in odds ratio values for the trend over the years for each laboratory per age of heel prick blood sampling, the pattern over the years was similar for each age of heel prick blood sampling for a specific laboratory (data not shown). Except for day is 7 for which the odds ratio values were in general higher compared to the other ages. In addition, for each lab in most years the odds ratio was statistically significantly above 1 (Online Supplemental Material 
A

nTSH $>1$

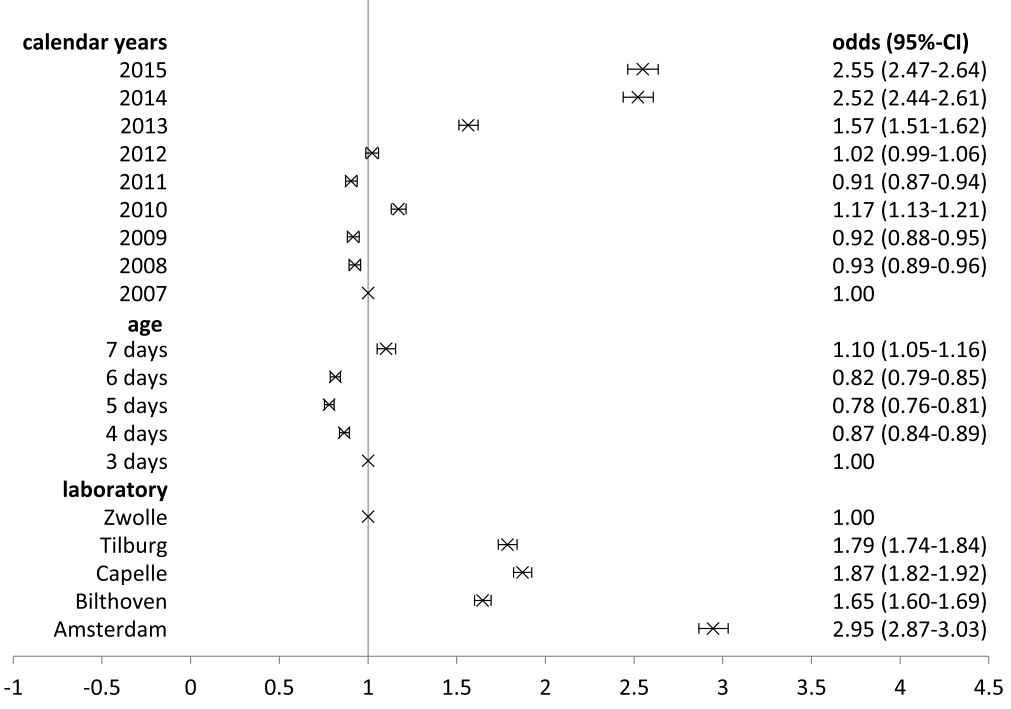

\section{B nTSH $>1$ - calendar year by laboratory}

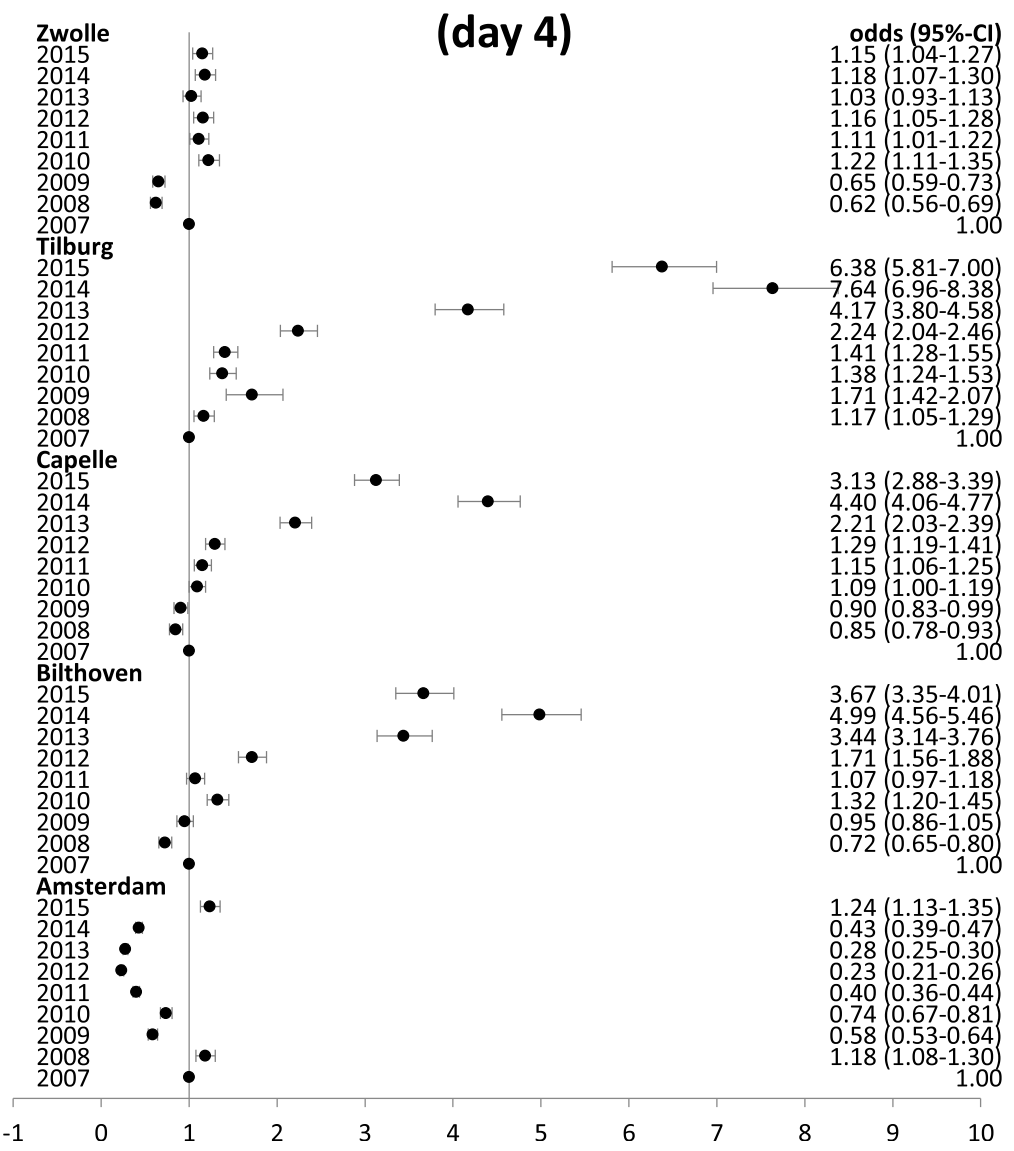

Fig. 2 (See legend on next page.) 
(See figure on previous page.)

Fig. 2 Odds ratio and their 95\% confidence intervals of exceeding blood spot screening cut off (nTSH $>1 \mathrm{mIU} / \mathrm{L}$ versus $n T S H=1 \mathrm{mIU} / \mathrm{L}$ ) for several characteristics, a univariate analyses, b multivariate analyses with the following characteristics (reference value): year (2007), laboratory (Zwolle), age of heel prick blood sampling (4 days), gender (male), birth weight category (middle: 3.31-3.71 kg), pregnancy duration category (middle: 276284 days), season (spring), and interaction terms: year*laboratory, age*year, age*laboratory; presented for age = day 4

Figure 1). In all laboratories, except Amsterdam, the odds ratios showed an increase starting in 2008-2009 compared to the reference year 2007. However this was not statistically significant in each year and for each laboratory (Fig. 3b). This means that the proportion children with $\mathrm{nTSH}>5 \mathrm{mIU} / \mathrm{L}$ tended to be (nonstatistically significant) higher in those years compared to 2007. In the Amsterdam laboratory the proportion children with nTSH. $5 \mathrm{mIU} / \mathrm{L}$ was higher compared to 2007 in 2010 and 2015 (statistically significant).

\section{Discussion}

Based on nTSH as indicator to assess a population's iodine status [23], the Dutch population is considered iodine sufficient between 2007 and 2015, with a prevalence of $\mathrm{nTSH}>5 \mathrm{mIU} / \mathrm{L}$ below 3\%, namely ranging at 0.6$1.3 \%$ depending on calendar year. These results confirm studies on urinary iodine content performed in a similar period in Doetinchem, the Netherlands [18]. In 2006, 2010 and 2015 the median 24-h iodine excretion was > $150 \mu \mathrm{g} / \mathrm{d}$ indicating an adequate iodine intake in the Dutch adult population. In several other countries nTSH was used to assess the population's iodine status as well. Our results are similar to Northern Ireland with an overall proportion of $0.49 \%$ with $\mathrm{nTSH}>5 \mathrm{mIU} / \mathrm{L}$ in 2003 2014 [30]. But higher proportions were observed in Belgium 2.6-3.3\% in 2009-2011 [9], Australia 4.1-9.7\% in 2001-2006 [31], Germany 14\% in 2005-2006 [32], and Latvia $8.4-16.5 \%$ in 2000-2002 [33]. Variation in iodine intake, but also differences in assessment of nTSH (e.g. sampling time, analytical method) or the cohort composition could be explanations for the observed variation. It is earlier indicated that several factors are associated with nTSH levels [28, 34, 35]. In our study, nTSH was statistically significantly associated with the laboratory performing the nTSH assay, age of heel prick sampling, gender, pregnancy duration, birth weight, and birth season. The magnitude of the differences was small for gender, pregnancy duration, birth weight and birth season, indicating that these were not the most relevant influencing factors in our data, but probably identified due to the large sample size.

For interpretation of the results and comparability between studies it is important to address some factors that potentially could have influenced the results. To minimize the effect of interfering factors in our study, we excluded premature born babies, as well as very early and late collection of heel prick blood samples. WHO states that heel prick blood samples should be taken on day 3 or $4[1,36]$. Similar to our study, several others used a more brought range of sampling days [9, 11, 37]. If we limit our analyses to day 3 and 4, the proportions with $\mathrm{nTSH}>5 \mathrm{mIU} / \mathrm{L}$ increased a little from $0.6-1.3 \%$ to $0.8-1.4 \%$, but remained overall below $3 \%$. Only for the laboratory of Amsterdam in 2015 the proportion increased to $3.1 \%$, which may indicate a potential mild iodine deficiency.

Based on conflicting conclusions regarding the iodine status studied with nTSH or urinary iodine concentration, some authors state that the current cut-off of $3 \%$

Table 4 Proportion (\%) new-borns with nTSH $>5$ mIU/L in heel prick blood by laboratory and calendar year and by age at heel prick sampling and calendar year (both Cochran-Mantel-Haenzel test)

\begin{tabular}{|c|c|c|c|c|c|c|c|c|c|c|}
\hline & 2007 & 2008 & 2009 & 2010 & 2011 & 2012 & 2013 & 2014 & 2015 & $p$-value \\
\hline \multicolumn{11}{|l|}{ Laboratory } \\
\hline Zwolle & 0.45 & 0.67 & 0.50 & 0.93 & 0.73 & 0.72 & 0.48 & 0.62 & 0.55 & 0.8723 \\
\hline Tilburg & 0.38 & 0.55 & 0.71 & 0.87 & 0.69 & 0.96 & 0.93 & 0.69 & 0.78 & 0.0018 \\
\hline Capelle & 0.44 & 0.63 & 0.72 & 0.97 & 0.80 & 0.96 & 0.77 & 0.69 & 0.78 & 0.0450 \\
\hline Bilthoven & 0.46 & 0.50 & 0.81 & 0.96 & 0.78 & 0.69 & 0.81 & 0.91 & 0.76 & 0.0157 \\
\hline Amsterdam & 1.40 & 1.59 & 1.55 & 2.44 & 1.41 & 1.31 & 0.96 & 1.14 & 2.58 & 0.3723 \\
\hline \multicolumn{11}{|l|}{ Age } \\
\hline day 3 & 0.81 & 1.13 & 0.97 & 1.7 & 0.62 & 0.95 & 0.89 & 0.99 & 1.28 & 0.8156 \\
\hline day 4 & 0.8 & 0.9 & 1.01 & 1.35 & 1.09 & 1.01 & 1.02 & 0.91 & 1.16 & 0.0681 \\
\hline day 5 & 0.54 & 0.7 & 0.71 & 0.85 & 0.67 & 0.91 & 0.5 & 0.78 & 0.93 & 0.0529 \\
\hline day 6 & 0.47 & 0.55 & 0.92 & 1.41 & 0.65 & 0.73 & 0.58 & 0.5 & 0.94 & 0.4966 \\
\hline day 7 & 0.15 & 0.76 & 0.64 & 1.33 & 1.02 & 0.89 & 0.36 & 0.77 & 1.1 & 0.029 \\
\hline
\end{tabular}


A

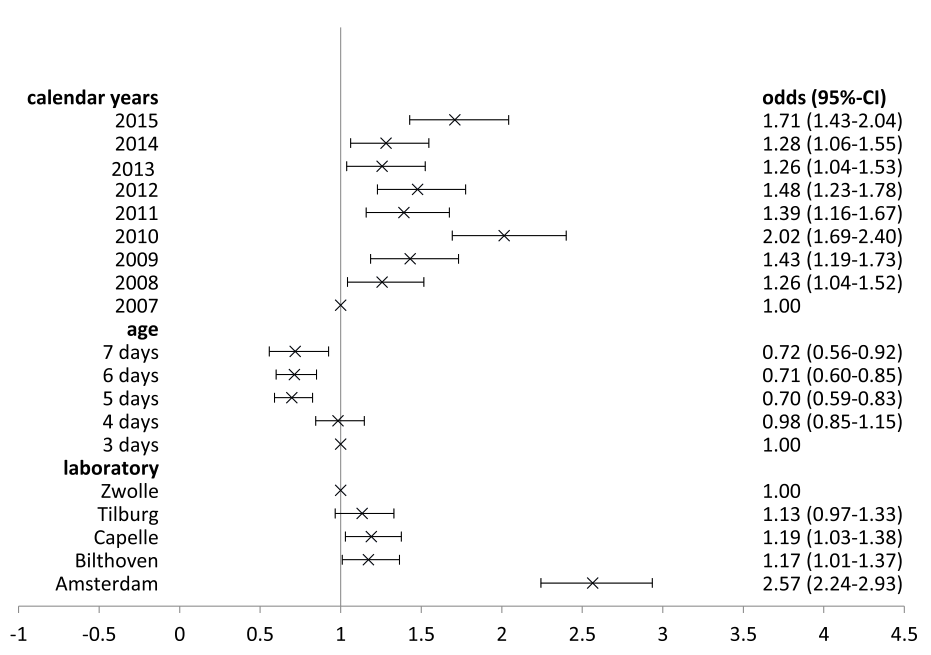

B nTSH $>5$ - calendar year by laboratory (day 4)

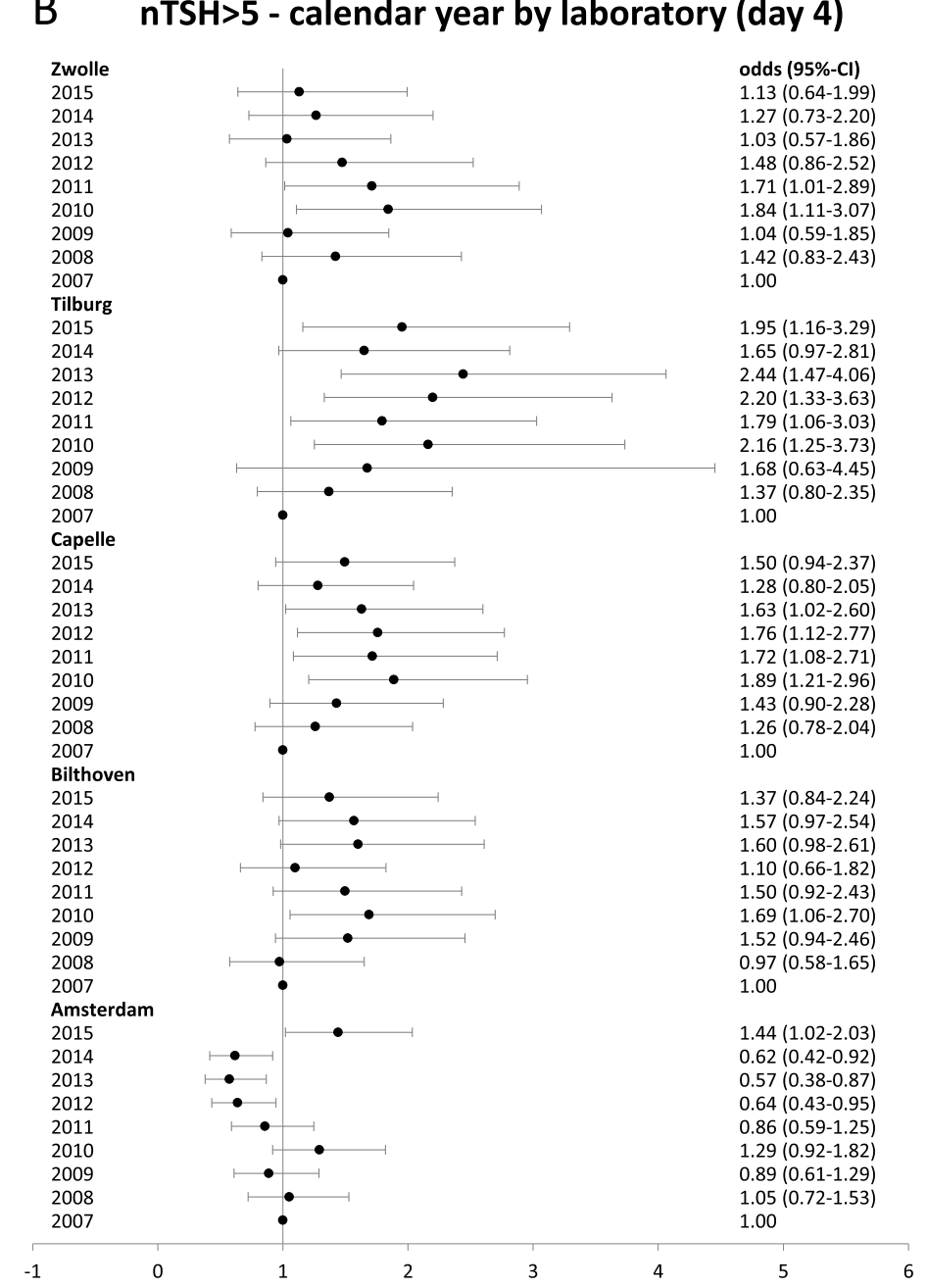

Fig. 3 (See legend on next page.)
$\mathrm{nTSH}>5$

(1.23-1.78)

$1.39(1.16-1.67)$

6 (1.04-1.52)

$0.72(0.56-0.92)$

$0.71(0.60-0.85)$

$0.98(0.85-1.15)$

(0.97-1.33)

1.19 (1.03-1.38)

$1.17(1.01-1.37)$

4.5 
(See figure on previous page.)

Fig. 3 Odds ratio and their 95\% confidence intervals of exceeding blood spot screening cut off (nTSH $>5 \mathrm{mIU} / \mathrm{L}$ versus $n T S H<=5 \mathrm{mIU} / \mathrm{L}$ ) for several characteristics, a univariate analyses, b multivariate analyses with the following characteristics (reference value): year (2007), laboratory (Zwolle), age of heel prick blood sampling (4 days), gender (male), birth weight category (middle: 3.31-3.71 kg), pregnancy duration category (middle: 276284 days), season (spring), and interaction terms: year*laboratory, age* year, age*laboratory; presented for age = day 4

frequency of $\mathrm{nTSH}>5 \mathrm{mIU} / \mathrm{L}$ is not sensitive enough to detect mild iodine deficiency $[9,38]$.

In some studies a lower cut off of $2 \mathrm{mIU} / \mathrm{L}$ is proposed to detect mild iodine deficiency. In our study the proportion children with $\mathrm{nTSH}>2 \mathrm{mIU} / \mathrm{L}$ ranged in 2007 2015 from $7.6-11.3 \%$. The proportions found in cohorts in Northern Ireland (6.2\%) [30] and Wales UK (10.9$11.9 \%$ ) [37] are similar. Higher proportions were observed in Belgium (21-40\%) [9]. It remains unclear how to interpret these results, as the Netherlands is considered iodine sufficient and for the other areas mild iodine deficiency among pregnant women is reported based on urinary iodine concentration. Also other issues may have resulted in the mentioned discrepancy of results between studies based on nTSH and urinary iodine concentration, for instance issues interfering with nTSH levels, besides maternal iodine intake, as described above. On the other hand, even though urinary iodine concentration is considered as a standard to assess population's iodine status there are also factors influencing the results. For instance using WHO's cut-offs for iodine concentration it is assumed that the mean urinary volume is $1.5 \mathrm{~L}$ for adults an $1 \mathrm{~L}$ for children; this is not the case for all populations [16, 39]. Higher urine volumes will dilute the iodine concentration what may result in incorrect conclusions on inadequacy. More research is required to get insight in the best way to interpret the nTSH values for predicting the population's iodine status. As far as we know no validity study is available providing a more absolute numeric value for the interpretation of $\mathrm{nTSH}$ in relation to population's iodine status, as indicated earlier by Burns et al. [40].

The second aim of our study was to pick up the reduction in iodine intake in the Dutch adult population in $\mathrm{nTSH}$ levels. As changes in the nTSH distribution may provide early indications of deterioration of the iodine status in pregnant women $[9,37,40,41]$, and could be interpreted as an early warning and a need for regular monitoring. Due to changes in the Dutch iodine policy in 2008 and 2012, as mentioned in the introduction, the maximum iodine level of iodized salt was reduced in order to allow more food groups to be produced with iodized salt without increasing the risk of excessive intakes [19]. The Dutch iodine intake of adults estimated from 24-h urine collections decreased between 2006 and 2010 on average $30 \%$ and remained stable until 2015 [18]. In Switzerland a $25 \%$ increase in iodine content of table salt improved the iodine status, which was observed in a decrease in proportion nTSH > $5 \mathrm{mIU} / \mathrm{L}$ of 2.9 to $1.7 \%$ [36]. In our study, an increase in proportion with $\mathrm{nTSH}>1 \mathrm{mIU} / \mathrm{L}$ was observed for four of the five laboratories, which might indicate a deterioration of the iodine status. For the proportion with $\mathrm{nTSH}>5 \mathrm{mIU} / \mathrm{L}$ no clear significant trend could be found. However, the variable laboratory was an important confounding factor and there was a strong interaction between laboratory and year. In our study, the analyses were therefore also showed results for each laboratory separately and used a multivariate regression model. The analytical measurements were performed with three different methods. $\mathrm{Li}$ et al. (2010) showed that there is a large range of nTSH assays with a broad variation in assay performance [34]. This will make it difficult to compare results measured with different assays. For three laboratories (Bilthoven, Capelle a/d IJssel, Tilburg) the analytical assay did change during the studied time-period and therefore a potential change in $\mathrm{nTSH}$ distribution can be related to change in iodine intake, but also to the new assay. In addition, as described in the methodology section, in the first years of introduction of the new assay, the nTSH levels were lower compared to the prior assay. However, this difference disappeared in later years and the earlier introduced correction factor was lapsed. This might be related to bias due to assay performance within the same assay, which remains unclear [34]. On the other hand, the increase in the proportion with $\mathrm{nTSH}>1 \mathrm{mIU} / \mathrm{L}$ for these three laboratories started around 2009, prior to this analytical change. For two laboratories the analytical assay was equal over the studied years, but different between the laboratories. A statistical significant increase in the proportion with nTSH $>1 \mathrm{mIU} / \mathrm{L}$ was found for the Zwolle laboratory starting round the year decreased iodine intake in the Dutch population was expected. This might indicate deterioration of iodine intake. However, no such trend was observed for the Amsterdam laboratory. It therefor remains unclear if the decreased iodine intake in the Dutch population would have affected the nTSH levels and could be picked-up.

The laboratory in Amsterdam, had the highest yearly proportion new-borns with nTSH $>5 \mathrm{mIU} / \mathrm{L}$ of about $1.0-2.6 \%$. In the other four laboratories this proportion was lower, varying from $0.4-1.0 \%$. It remains unclear whether this difference in proportion nTSH $>5$ is solely due to the different laboratory assays or that the population new-borns measured in the laboratory of Amsterdam do differ from the rest of the country. Based 
on the characteristics available in our study no differences between the Amsterdam region and the rest of the country could be identified explaining the larger proportion. In the most recent Dutch National Food Consumption Survey (2012-2016) no large differences in food consumption were observed between regions in the Netherlands [42].

Besides the already mentioned different nTSH assays in the laboratories and the change in assay in some laboratories this study has other limitations. The nTSH assays are developed for $\mathrm{CH}$ screening in new-borns. The cut-off values applied in this screening are higher (e.g. 10-20 mIU/L) than the cut-off value for assessing iodine status $(>5 \mathrm{mIU} / \mathrm{L})$. The performance of the assays may be different for these values. In addition, in the Dutch screening for congenital hypothyroidism, total $\mathrm{T}_{4}$ is measured for all neonates, and nTSH only for the circa $20 \%$ with the lowest total $\mathrm{T}_{4}$ concentrations. As total $\mathrm{T}_{4}$ concentration is associated with several characteristics in the study population, the nTSH-subpopulation is no representative sample of the total population (selection bias, see also Table 1). As total $\mathrm{T}_{4}$ concentration and nTSH are associated, it is expected that the proportion children with an elevated nTSH is to some extend overrepresented in this group. However, there are no indications that the overall associations with calendar year, day of heel prick sampling, and laboratory would different for both groups. Another limitation is the rounded nTSH values. For the congenital hypothyroidism screening, there was historically no need to retain the digits. To assess iodine status via nTSH it is recommended to retain some digits, to be able to better predict the proportions with a nTSH concentration above a specified cut-off level. For example, in our study, the proportion with $\mathrm{TSH}>5 \mathrm{mIU} / \mathrm{L}$ is an underestimation, as it does not include children with a nTSH concentration between 5.01 and $5.5 \mathrm{mIU} / \mathrm{L}$, as these were rounded to 5 $\mathrm{mIU} / \mathrm{L}$. Besides limitations this study has also some strengths. One strength is that a very large part of the newborns is included in the Dutch heel prick screening (>99\%), and that we have data available from a large time period (2007-2015). This made it possible to study the trend over time as well as performing sub-group analyses. Earlier Burns et al. stated that a trend in nTSH over years is informative in addition to the yearly numeric values [40]. Based on the results from our study we support this, given that the same nTSH assay is used over the years.

Based on the discussed limitations of the nTSHmarker, it is recommended to not base a conclusion on iodine status on this biomarker solely, but in combination with other biomarkers for population iodine status, e.g. repeated 24-h urinary iodine excretion of pregnant women in the Netherlands. Although urinary iodine concentration or 24-h urinary iodine excretion are generally proposed as most valid measurements, the assessment with these measures also have some assumptions or difficulties in the interpretations. For example the earlier mentioned assumption of a urinary volume of 1.5 $\mathrm{L} / \mathrm{d}$. As the nTSH-data from the Netherlands is readily available from the congenital hypothyroidism screening it can be used as a crude indicator for the iodine status in the Netherlands. To make it better usable for studying iodine status, it is recommended to retain the unrounded values for total T4 as well as nTSH. As pregnant women are vulnerable for iodine deficiency, due to increased requirements and the irreversible effects on the child's cognition, it is important to monitor their iodine status regularly.

\section{Conclusion}

The results show that the iodine status seems sufficient in the Netherlands. Whether the increased proportion $\mathrm{nTSH}>1 \mathrm{mIU} / \mathrm{L}$ could be interpreted as early indications of a deterioration of the iodine status remains unclear, mainly due to differences and changes in laboratory assays. Unless the flaws, next to other markers for iodine status, nTSH measured for congenital hypothyroidism screening might be valuable and inexpensive data to get a crude impression of the iodine status and the trend in time. But more research is needed to validate nTSH as indicator of population's iodine status and the potential conditions.

\section{Abbreviations \\ nTSH: neonatal Thyroid Stimulating Hormone; WHO: World Health \\ Organisation; CH: Congenital hypothyroidism; TBG: Thyroid-binding globulin}

\section{Supplementary Information}

The online version contains supplementary material available at https://doi. org/10.1186/s12937-021-00722-4.

\section{Additional file 1.}

\section{Acknowledgements}

I would like to thank Peter Schielen for sharing high valuable knowledge about the Dutch heel prick screening, Marjolein Geurts and Maarten

Schipper for performing preliminary analyses, and Alina Nicolaie for statistical advice.

Author's contributions

Janneke Verkaik-Kloosterman: responsible for the design, conducted statistical analyses, interpretation of the results, and drafted the manuscript. The author read and approved the final manuscript.

\section{Funding}

This research was funded by the Dutch Ministry of Public Health, Welfare and Sports (WWS).

Availability of data and materials

The data analyzed during the current study are available from Praeventis, but restrictions apply to the availability of these data, which were used under license for the current study, and so are not publicly available. 


\section{Declarations}

\section{Ethics approval and consent to participate}

Participating the neonatal screening parents give informed consent for registration of the results in Praeventis and the use for additional scientific research. A Praeventis working group evaluated our research protocol and provided the data. The Dutch neonatal heel prick (blot spot) screening program is part of the National Population Screening Programme in the Netherlands funded by the State and falls under the Dutch Population Screening Act. For our study no additional ethical approval was necessary, because neither extra specimens nor additional chemical analyses were required, in addition the provided dataset was anonymised, and consent for additional scientific research was provided. The data was provided by the working group management information of Praeventis. Praeventis is the registration system of the Dutch national vaccine provision and prevention program, which includes the neonatal screen.

\section{Consent for publication}

Not applicable.

\section{Competing interests}

The author declare that she has no competing interests

Received: 3 December 2020 Accepted: 19 June 2021

Published online: 04 July 2021

\section{References}

1. Andersson M, de Benoist B, Darnton-Hill I, Delange F. lodine deficiency in Europe. A continuing public health problem. Geneva: World Health Organisation Regional Office for Europe; 2007.

2. Pearce EN, Lazarus JH, Moreno-Reyes R, Zimmermann MB. Consequences of iodine deficiency and excess in pregnant women: an overview of current knowns and unknowns. Am J Clin Nutr. 2016;104(Suppl 3):918S-23S.

3. Bath SC, Steer CD, Golding J, Emmett P, Rayman MP. Effect of inadequate iodine status in UK pregnant women on cognitive outcomes in their children: results from the Avon Longitudinal Study of Parents and Children (ALSPAC). Lancet. 2013;382(9889):331-7.

4. Hynes $\mathrm{KL}$, Otahal P, Hay I, Burgess JR. Mild iodine deficiency during pregnancy is associated with reduced educational outcomes in the offspring: 9-year follow-up of the gestational iodine cohort. J Clin Endocrinol Metab. 2013;98(5):1954-62.

5. Hynes KL, Otahal P, Burgess JR, Oddy WH, Hay I. Reduced educational outcomes persist into adolescence following mild iodine deficiency in utero, despite adequacy in childhood: 15-year follow-up of the gestational iodine cohort investigating auditory processing speed and working memory. Nutrients. 2017;9(12):1354.

6. Moleti M, Trimarchi F, Tortorella G, Candia Longo A, Giorgianni G, Sturniolo $\mathrm{G}$, et al. Effects of maternal iodine nutrition and thyroid status on cognitive development in offspring: a pilot study. Thyroid. 2016;26(2):296-305.

7. Vanderpump MP, Lazarus JH, Smyth PP, Laurberg P, Holder RL, Boelaert K, et al. lodine status of UK schoolgirls: a cross-sectional survey. Lancet. 2011; 377(9782):2007-12

8. Vandevijvere S, Amsalkhir S, Mourri AB, Van Oyen H, Moreno-Reyes R. lodine deficiency among Belgian pregnant women not fully corrected by iodinecontaining multivitamins: a national cross-sectional survey. Br J Nutr. 2013; 109(12):2276-84

9. Vandevijvere S, Coucke W, Vanderpas J, Trumpff C, Fauvart M, Meulemans A, et al. Neonatal thyroid-stimulating hormone concentrations in Belgium: a useful indicator for detecting mild iodine deficiency? PLoS One. 2012;7(10): e47770.

10. Zimmermann MB, Andersson M. Prevalence of iodine deficiency in Europe in 2010. Ann Endocrinol. 2011;72(2):164-6.

11. Caylan N, Tezel B, Ozbas S, Sahin N, Aydin S, Deniz A, et al. Neonatal thyroid stimulating hormone screening as a monitoring tool for iodine deficiency in Turkey. J Clin Res Pediatr Endocrinol. 2016:8(2):187-91.

12. Rohner F, Zimmermann M, Jooste P, Pandav C, Caldwell K, Raghavan R, et al. Biomarkers of nutrition for development--iodine review. J Nutr. 2014 144(8):1322S-42S

13. de Benoist $B$, McLean $E$, Andersson M, Rogers L. lodine deficiency in 2007: global progress since 2003. Food Nutr Bull. 2008;29(3):195-202.
14. World Health Organization. Vitamin and Mineral Nutrition Information System (VMNIS) - WHO Global database on iodine deficiency: the Netherlands 2006 Available from: https://www.who.int/vmnis/iodine/data/ database/countries/nld idd.pdf?ua=1.

15. Verkaik-Kloosterman J, Buurma-Rethans EJM, Dekkers ALM, van Rossum CTM. Decreased, but still sufficient, iodine intake of children and adults in the Netherlands. Br J Nutr. 2017;117(7):1020-31.

16. Hendriksen MA, van Raaij JM, Geleijnse JM. Wilson-van den Hooven C, Ocke $M C$, van der AD. Monitoring salt and iodine intakes in Dutch adults between 2006 and 2010 using $24 \mathrm{~h}$ urinary sodium and iodine excretions. Public Health Nutr. 2014:17(7):1431-8.

17. Anonymous. Covenant use bakkery salt [in Dutch: Convenant gebruik bakkerszout]. Staatscourant. 2008:209:1-3

18. Hendriksen M, Etemad Z, Van den Bogaard CHM, et al. Salt, iodine and potassium intake 2015. In: Nutritional status research among adults in Doetinchem [in Dutch: Zout-, jodium-, en kaliuminname 2015. Voedingsstatusonderzoek bij volwassenen uit Doetinchem]. Bilthoven: RIVM; 2016. Report No.: RIVM Briefrapport 2016-0081.

19. Anonymous. Decision of 13 June 2018, revision of commodity act resolution Addition of micronutrients to foods, related to the addition of iodine [in Dutch: Besluit van 13 juni 2008, houdende wijziging van het Warenwetbesluit Toevoeging micro-voedingsstoffen aan levensmiddelen, inzake het toevoegen van jodium]. Staatsblad van het Koninkrijk der Nederlanden. 2008:257:1-5.

20. WHO. Urinary iodine concentrations for determining iodine status in populations. 2013. Contract No.: WHO/NMH/NHD/EPG/13.1.

21. Ristic-Medic D, Piskackova Z, Hooper L, Ruprich J, Casgrain A, Ashton K, et al. Methods of assessment of iodine status in humans: a systematic review. Am J Clin Nutr. 2009;89(6):2052S-69S.

22. Zimmermann MB. Methods to assess iron and iodine status. Br J Nutr. 2008; 99(Suppl 3):S2-9.

23. WHO. Assessment of iodine deficiency disorders and monitoring their elimination: World Health Organisation Regional Office for Europe; 2008

24. Verkerk PH, van Trotsenburg AS, Hoorweg-Nijman JJ, Oostdijk W, van Tijn DA, Kempers MJ, et al. Neonatal screening for congenital hypothyroidism: more than 30 years of experience in the Netherlands [in Dutch: Neonatale screening op congenitale hypothyreoïdie. Ruim 30 jaar ervaring in Nederland]. Ned Tijdschr Geneeskd. 2014;158:A6564.

25. Van Lier A, Oomen P, De Hoogh P, Drijfhout I, Elsinghorst B, Kemmeren J, et al. Praeventis, the immunisation register of the Netherlands: a tool to evaluate the national immunisation Programme. Euro Surveill. 2012:17:17.

26. Schönbeck Y, Rijpstra A, Verkerk PH. National heelprick screening - monitor 2014. Zeist: TNO; 2015. [in Dutch: Nationale hielprikscreening - Monitor 2014]. Report No: TNO/CH 2015 R11437

27. Schönbeck Y, Verkerk PH. The national heelprick screening monitor [in Dutch: De neonatale hielprik screening monitor 2015]. Zeist: TNO; 2016.

28. Trumpff C, Vandevijvere S, Moreno-Reyes R, Vanderpas J, Tafforeau J, Van Oyen $\mathrm{H}$, et al. Neonatal thyroid-stimulating hormone level is influenced by neonatal, maternal, and pregnancy factors. Nutrition research. 2015;35(11): 975-81

29. Peters C, van Trotsenburg ASP, Schoenmakers N. Diagnosis of endocrine disease: congenital hypothyroidism: update and perspectives. Eur J Endocrinol. 2018;179(6):R297-317.

30. Mullan K, Patterson C, Doolan K, Cundick J, Hamill L, McKeeman G, et al. Neonatal TSH levels in Northern Ireland from 2003 to 2014 as a measure of population iodine status. Clin Endocrinol. 2018;89(6):849-55.

31. Rahman A, Savige GS, Deacon NJ, Francis I, Chesters JE. Increased iodine deficiency in Victoria, Australia: analysis of neonatal thyroid-stimulating hormone data, 2001 to 2006. Med J Aust. 2010;193(9):503-5.

32. Ittermann $T$, Volzke $H$, Krey A, Remer T, Heckmann M, Lange A, et al. Median urinary iodine concentration reflected sufficient iodine supply in neonates from Northeast Germany in 2005-2006. Eur J Nutr. 2019;58(5):1815-20.

33. Gyurjyan RH, Lugovska R, Vevere P, van der Haar F. Newborn thyrotropin screening confirms iodine deficiency in Latvia. Eur J Clin Nutr. 2006;60(5): 688-90.

34. Li M, Eastman CJ. Neonatal TSH screening: is it a sensitive and reliable tool for monitoring iodine status in populations? Best Pract Res Clin Endocrino Metab. 2010;24(1):63-75.

35. Zhang Y, Du C, Wang W, Chen W, Shao P, Wang C, et al. Effect of maternal and neonatal factors on neonatal thyroid stimulating hormone: results from 
a population-based prospective cohort study in China. J Trace Elem Med Biol. 2018;49:151-6.

36. Zimmermann MB, Aeberli I, Torresani T, Burgi H. Increasing the iodine concentration in the Swiss iodized salt program markedly improved iodine status in pregnant women and children: a 5-y prospective national study. Am J Clin Nutr. 2005;82(2):388-92.

37. Evans C, Barry Nix A, Hillier S, Moat SJ. Neonatal blood TSH concentration in Wales (UK): an indicator of iodine sufficiency. Clin Endocrinol. 2014;81(4): 606-9.

38. Wassie MM, Yelland LN, Smithers LG, Ranieri E, Zhou SJ. Comparison of iodine status pre- and post-mandatory iodine fortification of bread in South Australia: a population study using newborn thyroid-stimulating hormone concentration as a marker. Public Health Nutr. 2019;22(16):3063-72.

39. Beckford K, Grimes CA, Margerison C, Riddell LJ, Skeaff SA, West ML, et al. A systematic review and meta-analysis of 24-h urinary output of children and adolescents: impact on the assessment of iodine status using urinary biomarkers. Eur J Nutr. 2019.

40. Burns R, Mayne PD, O'Herlihy C, Smith DF, Higgins M, Staines A, et al. Can neonatal TSH screening reflect trends in population iodine intake? Thyroid 2008;18(8):883-8.

41. Travers CA, Guttikonda K, Norton CA, Lewis PR, Mollart LJ, Wiley V, et al. lodine status in pregnant women and their newborns: are our babies at risk of iodine deficiency? Med J Aust. 2006;184(12):617-20.

42. National Institute for Public Health and the Environment. Food Consumption Survey [in Dutch: Voedselconsumptiepeiling]. Bilthoven: National Institute for Public Health and the Environment; 2018. Available from: https://www.wateetnederland.nl/

\section{Publisher's Note}

Springer Nature remains neutral with regard to jurisdictional claims in published maps and institutional affiliations.

Ready to submit your research? Choose BMC and benefit from:

- fast, convenient online submission

- thorough peer review by experienced researchers in your field

- rapid publication on acceptance

- support for research data, including large and complex data types

- gold Open Access which fosters wider collaboration and increased citations

- maximum visibility for your research: over $100 \mathrm{M}$ website views per year

At BMC, research is always in progress.

Learn more biomedcentral.com/submissions 